\title{
Theoretical and Experimental Stress-Strain Analysis of Compressed Steel Members with Closed Cross-Sections
}

\author{
Michal Tomko, Mohamad Al Ali, Ivo Demjan \\ Technical University of Košice \\ Civil Engineering Faculty, Institute of Structural Engineering \\ e-mail:michal.tomko@tuke.sk,mohamad.alali@tuke.sk,ivo.demjan@tuke.sk
}

\begin{abstract}
The paper presents fundamental information about experimental and theoretic-numerical research to determinate the load-carrying capacity of thin-walled cold-formed compressed steel members. The investigated members have closed cross-sections made from homogeneous materials. The theoretic-numerical analysis in this paper is oriented on the modeling of the initial deviations effects, caused by production process, on the load-carrying capacities of mentioned members, while the experimental investigation is to verify the theoretical results and to investigate the behavior of mentioned members during the loading process.
\end{abstract}

Key words: Load-carrying capacity, initial deviations, thin-walled cold-formed profiles

\section{Introduction}

Theory and design development of steel thin-walled cold-formed members and profiles creates a certain knowledge base for their practical application in the civil engineering. However, this fact does not mean that all complicated and challenging processes of their behavior, during the strain, transformation and failure are sufficiently investigated. From the material and geometric point of view, the thin-walled cold-formed profiles have specific specialties, which must be responsibly taken into account in their design.

From this aspect, the local stability requirements related to unfavorable buckling effects of their compressed parts are very significant. Favorable effects, related to membrane stresses and post-critical behavior are also important. Different calculation procedures in different standards (STN 73 1402:1988, STN EN 1993-1-3: 2006), reciprocal comparison of the results and their confrontation with existing experimental results indicate the need for further theoretical and experimental investigation of the post-critical behavior and elastic-plastic resistance of thin-walled profiles. 


\section{Description of the testing members}

In general, the experimental research program included 18 thin-walled cold-formed testing members with close cross-sections. The testing members were divided to two cross-sectional groups:

- Group A: with square cross-sections,

- Group B: with rectangular cross-sections; see Figure 1.

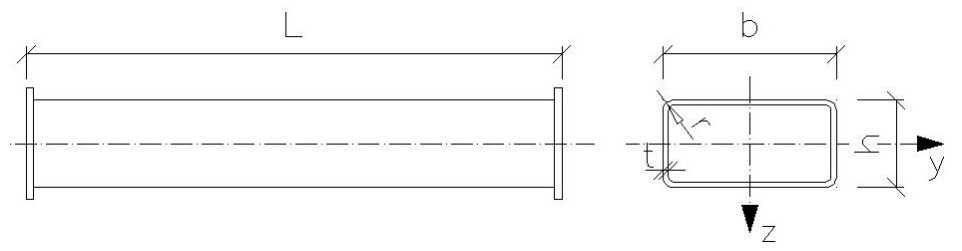

Figure 1: The scheme of testing members, Group B

The closed cross-sections and different dimensions of the testing members were mainly chosen to reflect the post-critical behavior of the several thin webs and to present the interaction of the adjacent sides in the strain, transformation and failure processes. The geometrical dimensions and description of the designed testing members of group B are given by Table 1 . The basic geometrical characteristics of the designed testing members, calculated according to the standards EN 1993-1-3 and STN 731402 are given by Table 2 .

Table 1: Geometrical dimensions of the designed members, group B

\begin{tabular}{|c|c|c|c|c|c|c|c|c|}
\hline \multicolumn{3}{|c|}{ Testing members } & \multicolumn{5}{|c|}{ Geometrical dimensions [mm] } & Steel \\
\hline Cross- & group & Marking & $\mathrm{b}$ & $\mathrm{h}$ & $\mathrm{t}$ & $\mathrm{r}$ & $\mathrm{L}$ & \multirow{3}{*}{ S235 } \\
\hline \multirow[b]{2}{*}{ B } & 1 & B11, B12, B13 & 150 & 100 & \multirow[b]{2}{*}{2} & \multirow[b]{2}{*}{3} & 450 & \\
\hline & $\begin{array}{l}2 \\
3\end{array}$ & $\begin{array}{l}\mathrm{B} 21, \mathrm{~B} 22, \mathrm{~B} 23 \\
\mathrm{~B} 31, \mathrm{~B} 32, \mathrm{~B} 33\end{array}$ & $\begin{array}{l}200 \\
200\end{array}$ & $\begin{array}{l}100 \\
150\end{array}$ & & & $\begin{array}{l}650 \\
600\end{array}$ & \\
\hline
\end{tabular}

Table 2: Basic geometrical characteristics of the designed testing members, group B

\begin{tabular}{|c|c|c|c|c|c|c|c|c|c|}
\hline \multirow{2}{*}{ Cross-sectional group } & \multicolumn{4}{|c|}{ STN EN 1993-1-3:2006 } & \multicolumn{4}{c|}{ STN 73 1402:1988 } \\
\cline { 3 - 9 } & & $\beta_{\mathrm{b}}$ & $\beta_{\mathrm{h}}$ & $\lambda_{\mathrm{y}}$ & $\lambda_{\mathrm{z}}$ & $\beta_{\mathrm{b}}$ & $\beta_{\mathrm{h}}$ & $\lambda_{\mathrm{y}}$ & $\lambda_{\mathrm{z}}$ \\
\hline \multirow{3}{*}{$\mathrm{B}$} & 1 & 73,12 & 48,12 & 10,70 & 7,87 & 71,00 & 46,00 & 10,74 & 7,89 \\
& 2 & 98,12 & 48,12 & 15,01 & 8,84 & 96,00 & 46,00 & 15,05 & 8,85 \\
& 3 & 98,12 & 73,12 & 9,58 & 7,71 & 96,00 & 71,00 & 9,60 & 7,72 \\
\hline
\end{tabular}

In the terms of local-stability classification, the webs of individual members are thin-walled at the compression strain. The members' lengths were designed from the global stability point of view, in order to decide of the members' local (cross-sectional) resistance.

All testing members were made out from steel sheets with nominal thickness $2 \mathrm{~mm}$ (steel S235). Three material pieces were taken from each used steel sheet to make normative shaped 
testing specimens. The testing specimens underwent a tension tests to find out the stress-strain diagrams and the actual material characteristics of applied steels.

Detailed dimension measuring of the testing members was done before the loading tests, in order to consistent evaluation and analyses of the experimental knowledge and results. The dimensions of cross-sections: width $b$, height $h$, and thickness $t$ were measured on the top, middle and bottom of each member. The radius $r$ was measured at each curved corner and the length $L$ was measured at each member's side. The average values of the measured dimensions were considered as actual; see Table 3.

Table 3: Average dimensions values and actual material characteristics

\begin{tabular}{|c|c|c|c|c|c|c|c|}
\hline \multirow{2}{*}{ Member } & $b$ & $h$ & $t$ & $r$ & $L$ & $f_{y}$ & $f_{u}$ \\
\cline { 2 - 8 } & \multicolumn{6}{|c|}{$[\mathrm{mm}]$} \\
\hline B11 & 157,12 & 102,52 & 2,11 & 3,0 & 450,70 & 241,00 & 360,67 \\
B12 & 157,93 & 102,43 & 2,11 & 3,0 & 450,03 & 241,00 & 360,67 \\
B13 & 159,37 & 101,83 & 2,11 & 3,0 & 450,03 & 241,00 & 360,67 \\
B21 & 207,93 & 103,08 & 2,12 & 3,0 & 650,00 & 242,33 & 360,00 \\
B22 & $\mathbf{2 0 7 , 4 7}$ & $\mathbf{1 0 3 , 1 8}$ & $\mathbf{2 , 1 0}$ & $\mathbf{3 , 0}$ & $\mathbf{6 4 9 , 8 8}$ & $\mathbf{2 4 2 , 3 3}$ & $\mathbf{3 6 0 , 0 0}$ \\
B23 & $\mathbf{2 0 7 , 3 5}$ & $\mathbf{1 0 2 , 6 2}$ & $\mathbf{2 , 1 6}$ & $\mathbf{3 , 0}$ & $\mathbf{6 4 9 , 2 5}$ & $\mathbf{2 4 2 , 3 3}$ & $\mathbf{3 6 0 , 0 0}$ \\
B31 & 206,98 & 152,57 & 2,10 & 3,0 & 600,25 & 240,00 & 358,33 \\
B32 & 207,13 & 152,50 & 2,11 & 3,0 & 599,75 & 240,00 & 358,33 \\
B33 & 206,90 & 153,13 & 2,14 & 3,0 & 599,50 & 240,00 & 358,33 \\
\hline
\end{tabular}

\section{Description of the testing methodology}

During consecutive programmed loading of the tested members, the strains $\varepsilon$ were measured in the middle cross-sections. The deflections (buckling) of the webs $w$ were measured in different places, according to the members' lengths. The resistive tensiometers were used to measure the strains $\varepsilon$ by means of measuring apparatus Hottinger Balwin UPM 60, connected to the computer for direct evaluation. The webs' deflections $w$ were measured using inductive sensors connected to the computer, also for direct evaluation.

The members during the test were consecutively loaded and released. Each member's loading process was regulated close to its real behavior, measured values of strains $\varepsilon$ and deflections of the webs $w$. The test continued up to total failure, defined by the beginning of consecutive, continuous increasing of strains $\varepsilon$ and deflections of the webs $w$.

According to the research targets, the initial buckling shapes of all testing members' webs were measured on previously drawn raster, by means of inductive sensors before testing start. The final buckling shapes, after test finishing were also found out.

General arrangement of the experimental trials at measuring strain $\varepsilon$ and wall deflection $w$ along the element B22 is shown in Figure 2.

Table 4 presents the theoretically calculated and experimentally determined values of the individual members' limit loads. All limit loads were calculated according to real-measured 
dimensions and determined yield stresses. According to Table 4, it is evident that the experimentally determined values are smaller than the expected theoretical values, which were calculated in accordance with the relevant standards. This serious fact may incur in consequence of the unfavorable development of the initial deviations. This unfavorable influence of the initial deviations is analyzed in detail in the next chapter of the paper.
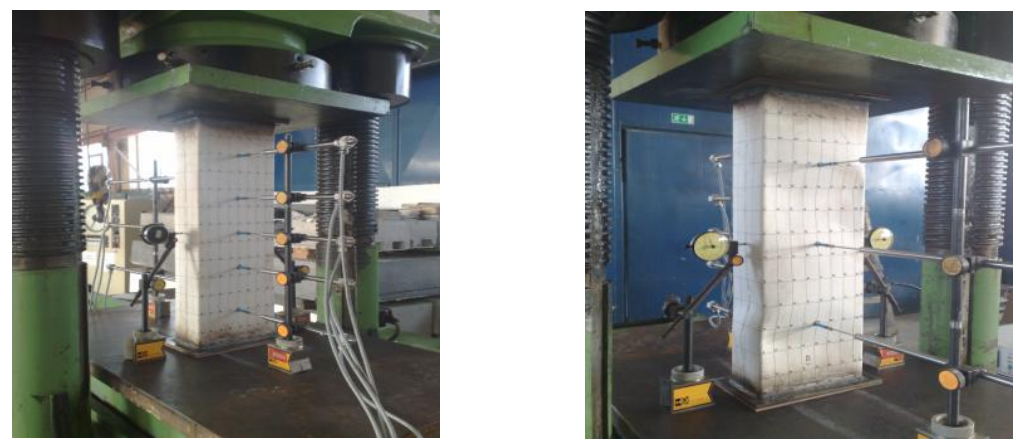

Figure 2: General arrangement of the tests - test element B22

Table 4: Theoretical and experimental limit loads

\begin{tabular}{|c|c|c|c|c|c|c|c|c|c|}
\hline \multirow{2}{*}{ Member } & $\mathrm{N}_{\mathrm{pl}, \mathrm{STN}}$ & $\mathrm{N}_{\mathrm{pl}, \mathrm{EN}}$ & $\mathrm{N}_{\mathrm{ul}, \mathrm{el}, \mathrm{STN}}$ & $\mathrm{N}_{\mathrm{ul}, \mathrm{el}, \mathrm{EN}}$ & $\mathrm{N}_{\mathrm{u}, \mathrm{y}, \mathrm{STN}}$ & $\mathrm{N}_{\mathrm{u}, \mathrm{y}, \mathrm{EN}}$ & $\mathrm{N}_{\mathrm{u}, \mathrm{Z}, \mathrm{STN}}$ & $\mathrm{N}_{\mathrm{u}, \mathrm{z}, \mathrm{EN}}$ & $\mathrm{N}_{\mathrm{u}, \mathrm{exp}}$ \\
\cline { 2 - 10 } & \multicolumn{8}{|c|}{$[\mathrm{kN}]$} \\
\hline B11 & 257,27 & 254,62 & 217,26 & 187,42 & 217,26 & 187,42 & 217,26 & 187,42 & 159,45 \\
B12 & 258,02 & 255,36 & 217,45 & 187,51 & 217,45 & 187,51 & 217,45 & 187,51 & 165,83 \\
B13 & 258,19 & 255,55 & 216,69 & 186,66 & 216,69 & 186,66 & 216,69 & 186,66 & 158,39 \\
B21 & 312,08 & 309,4 & 229,3 & 194,45 & 229,3 & 194,45 & 229,3 & 194,45 & 171,15 \\
B22 & $\mathbf{3 0 9 , 2 8}$ & $\mathbf{3 0 6 , 6 2}$ & $\mathbf{2 2 6 , 3}$ & $\mathbf{1 9 1 , 7 6}$ & $\mathbf{2 2 6 , 3}$ & $\mathbf{1 9 1 , 7 6}$ & $\mathbf{2 2 6 , 3}$ & $\mathbf{1 9 1 , 7 6}$ & $\mathbf{1 7 3 , 2 7}$ \\
B23 & $\mathbf{3 1 6 , 6 3}$ & $\mathbf{3 1 3 , 9 3}$ & $\mathbf{2 3 4 , 7 9}$ & $\mathbf{2 0 0 , 5 5}$ & $\mathbf{2 3 4 , 7 9}$ & $\mathbf{2 0 0 , 5 5}$ & $\mathbf{2 3 4 , 7 9}$ & $\mathbf{2 0 0 , 5 5}$ & $\mathbf{1 6 4 , 7 7}$ \\
B31 & 355,59 & 352,96 & 234,82 & 201,00 & 234,82 & 201,00 & 234,82 & 201,00 & 195,59 \\
B32 & 356,61 & 353,97 & 235,94 & 201,98 & 235,94 & 201,98 & 235,94 & 201,98 & 184,97 \\
B33 & 363,52 & 360,86 & 243,57 & 208,89 & 243,57 & 208,89 & 243,57 & 208,89 & 204,10 \\
\hline
\end{tabular}

Where, $N_{p l} \quad$ the local plastic limit load of full cross-section, defined by attaining the yield
stress $f_{y}$,

$N_{u l, e l} \quad$ the local (post-critical) elastic limit load of effective cross-section, defined by attaining the yield stress $f_{y}$,

$N_{u, y}, N_{u, z} \quad$ the buckling limit load of a member with effective cross-section, according to

The above mentioned theoretical limit loads with the indexes (STN) were calculated according to the chapters VI/41 and VI/44 of the Slovak Technical standard STN 73 1402:1988, considering the chapter 6/6.8.1 of the standard STN 73 1401:1998. The theoretical limit loads with the indexes (EN) were calculated according to the chapter 5/5.1 - 5/5.5.2 and 6/6.2 of the European standard STN EN 1993-1-3:2006, considering the chapter 4/4.1 - 4/4.4 of the standard STN EN 1993-1-5:2006 and chapter 6/6.3.1 of the standard STN EN 1993-11:2006. 


\section{Calculation models and the experiment simulation}

Calculation models of the testing members, described in Table 3, were created using programming environment based on FEM - software ANSYS. The target of FEM analysis was to obtain more accurate data about the post-critical behavior of the mentioned members, to determine their limit loads and to compare them with the experimental results. In this paper, the obtained analysis results are compared with the theoretical and experimental limit loads of the actual testing members B22 and B23.
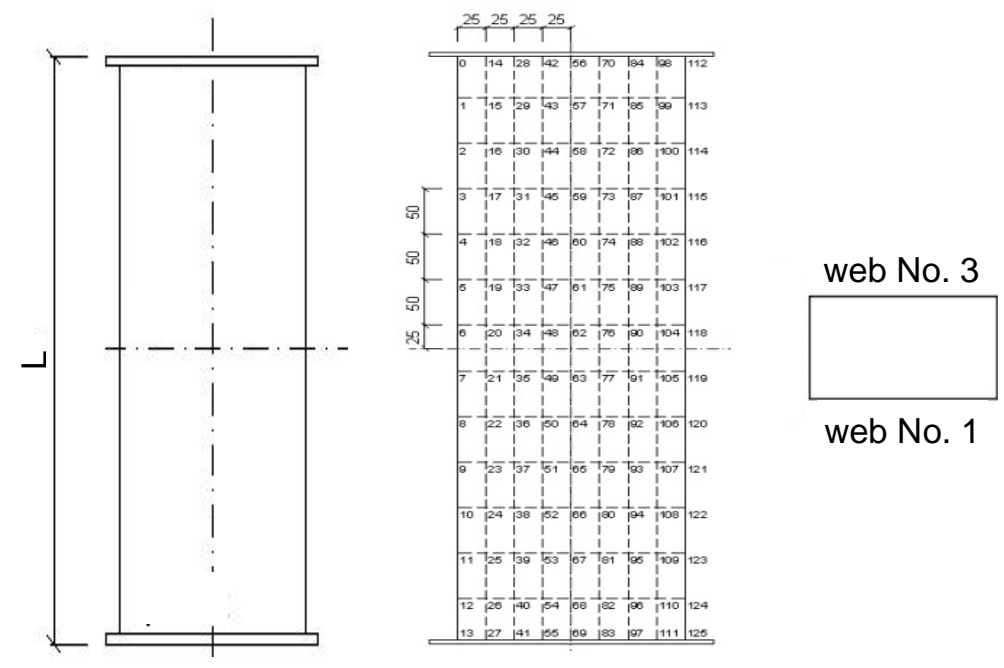

Figure 3: Layout of the generated grid, B22 and B23

The volume shell elements SOLSH190 were applied to create the calculation models. The finite element SOLSH190 is usually used for the simulation of shell structures with wide range of thicknesses (from thin to medium thickness). This element, with eight connecting nodes, has three degrees of freedom at each node. The element may be used to solve the geometrical and physical nonlinear problems. This type may be also used for the composite multilayer modeling (up to 250 different material's layers).

The modeling was carried out with considering the initial deviations. Figure 3 illustrates the concept of generated grid. The values of the measured initial deviations in individual grid points (member B22).

Each of the 3D calculation models (B22 and B23) contains 4182 nods and 4100 shell elements. Boundary conditions of the modeled, axially compressed members were defined by two-sided hinged connections.

Two types of calculation models were used to verify the initial deviations effect:

- With the consideration of the webs' initial deviation,

- Without the consideration of the webs' initial deviation.

Elastic-plastic material with hardening was considered with the using of plastic zones method. This material is characterized by a bilinear approximation of the strain-stress diagram of steel with yield stress $f_{y}=242,33 \mathrm{MPa}$ and hardening modulus $E_{\text {hard }}=2800 \mathrm{MPa}$. 
The modeling of testing members was carried out according to above mentioned description. The general configuration of modeled testing member B22 is illustrated in Figure 4.

Figure 4 contains 3D views, the generated grid for initial deviations defining and the finite element mesh of volume shell elements SOLSH190. According to Table 3, the member B22 has a dimensions: $b \times h \times t / L=207,47 \times 103,18 \times 2,1 / 649,88$ [mm].
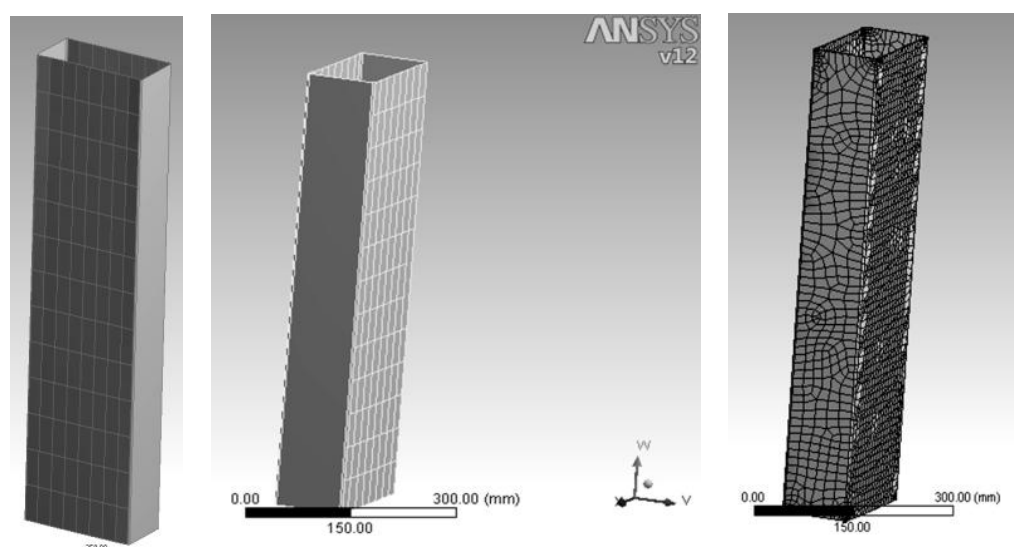

Figure 4: Configuration of the calculation model, member B22

The analysis was carried out with sequentially increasing the applied load until the first appearance of plastic zones locations. The applied load was transformed to the middle-plane of the shell elements. The model was analyzed using the geometrical and physical non-linear calculation.

\section{Results and their analysis}

The final webs' buckling shapes in topographical form, together with the equivalent elastic strain of modeled member B22 is presented in Figure 5.
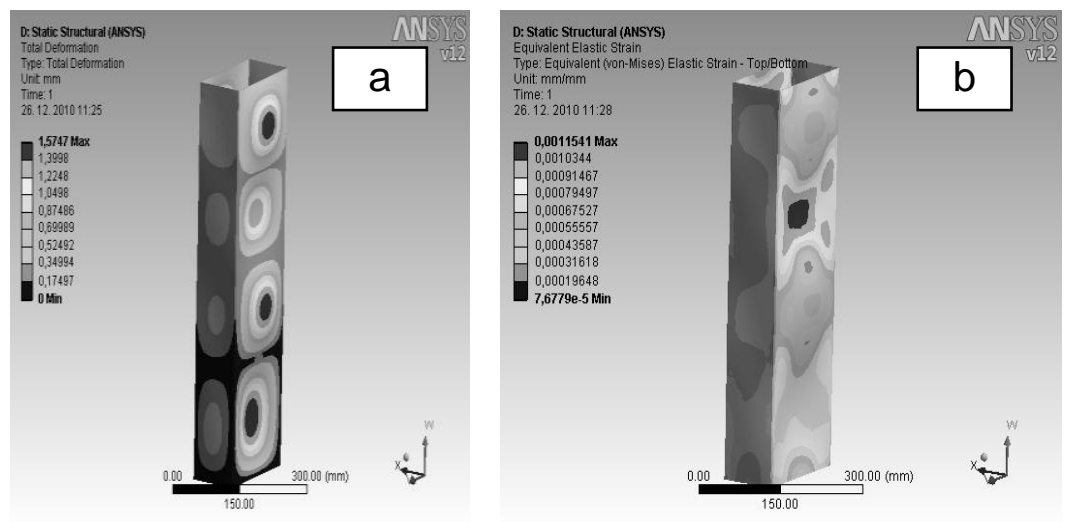

Figure 5: Final deformation (a) and equivalent elastic strain (b), B22 
The comparison of the several limit loads obtained by the theoretical, FEM simulation and experimental investigation are illustrated in Figure 6.

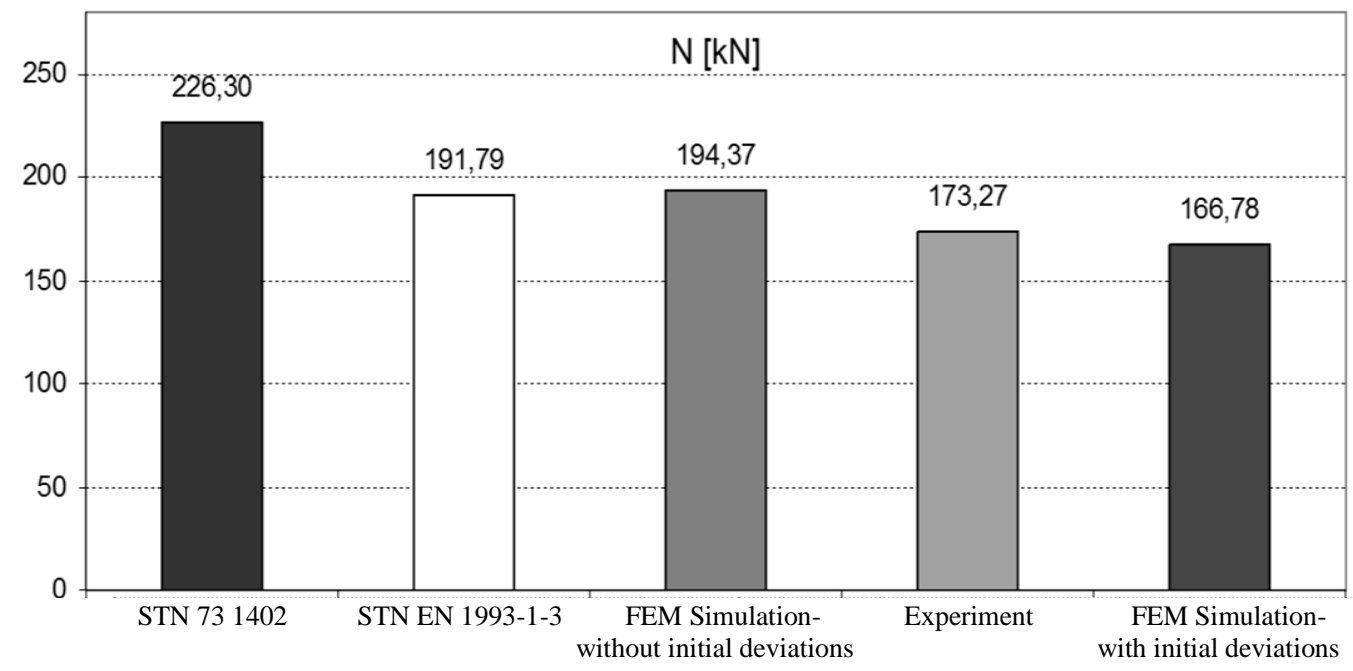

Figure 6: Comparison of the several limit loads, B22

Iteration process with small increments of loading was needed to use for the finding the listed development level of plastic zones. Suitable procedure of sequential loading was used to find the first plastic zone on the internal surface of the web. By the continuation with a sequential loading, the development of plastic zones was manifested on the external surface of the web too. Further overloading effected a broadening of the plastic zones by the web's surface in about $1 / 3$ of the member's length. The sequential loading was monitored until the divergence of the calculation (the collapse of member).

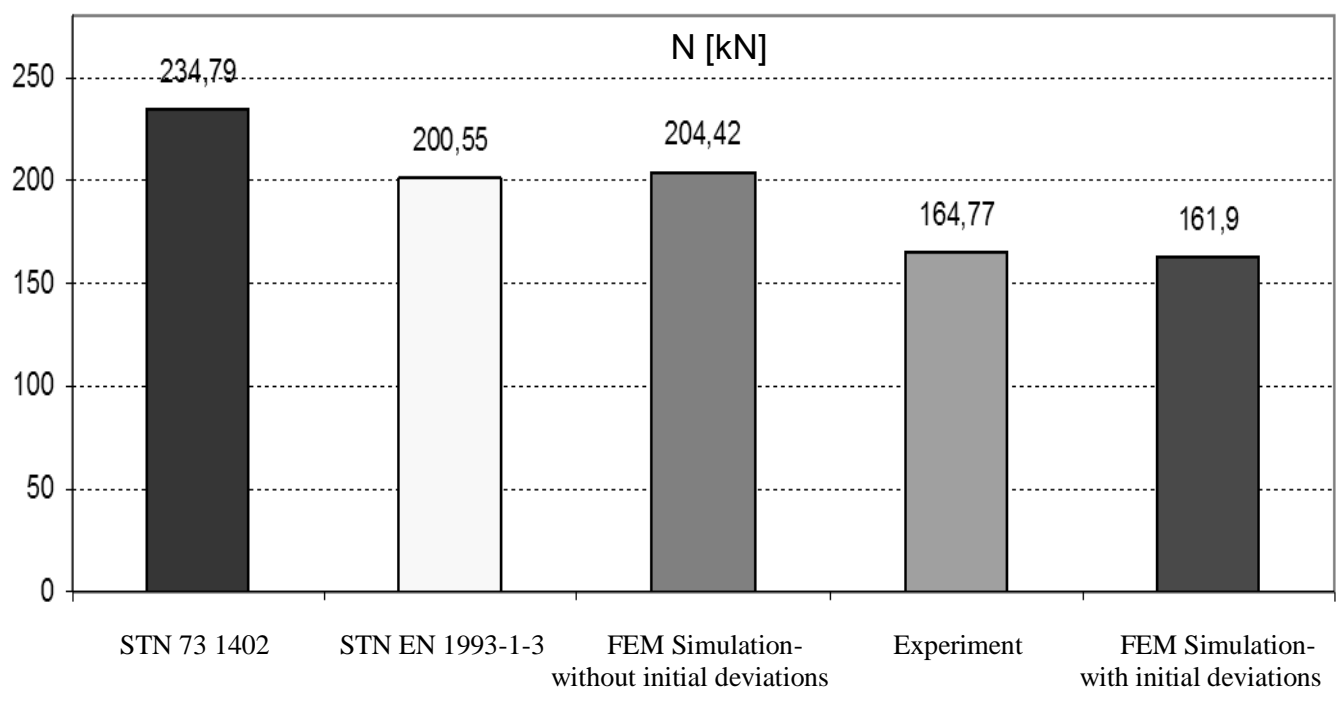

Figure 17: Comparison of the several limit loads, B23 


\section{Conclusion}

The total resistances of the testing members, together with their actual behavior during transformation and failure process were investigated by means of theoretic-numerical analysis and experimental verification. On the basis of the obtained experimental results and those acquired from the calculation models and analysis, it is evident that the resistances of the compressed thin-walled elements are significantly influenced by the initial deviations and/or by the initial buckling shapes of their individual webs.

Figures 6 and 7 indicate the results conformity between FEM simulation and theoretical calculation according to STN EN 1993-1-3:2006 - without taking into account the initial deviations. These figures also indicate the results conformity between FEM simulation and experiment results - with taking into account the initial deviations. The different in the results between the standard STN 73 1402:1998 and STN EN 1993-1-3:2006 is 14,58 \%. However, the FEM simulation proves that the calculation procedures in the standards are not enough sufficient for the consideration of the initial deviations influence.

\section{Acknowledgements}

This paper is supported by the project "Centre of excellent research of progressive building structures, materials and technologies", based on the Operational program Research and development, financed by the European Regional Development Fund of the European Union.

\section{References}

[1] Juhás P. (1973). Mechanics of deformations and violations of supporting steel parts - plastics deformations. Final report of the research project. P-12-124-003-02/7c. ÚSTARCH SAV, Bratislava.

[2] Juhás P. (1974). Resistance walls printed steel rods. In: Proceedings of the Conference: The stability of components and systems. DT SVTS, Bratislava, s. 160-166.

[3] Juhás P., Al Ali M. \& Kokorud'ová Z. (2010). Local stability and carrying capacity of thinwalled compressed members. In: Challenges, Opportunities and Solutions in Structural Engineering and Construction, Las Vegas, USA 2009. London: Taylor \& Francis Group, p. 149-155. ISBN 978-0-415-56809-8.

[4] Kmet' S. \& Tomko M. (2009). Analysis of large-span steel suspended members subjected to tension and bending. In: Civil, Structural and Environmental Engineering Computing: Proceedings of the Twelfth International Conference: Funchal - Madeira - Portugal, 1-4 September 2009. Kippen: Civil-Comp Press,. p. 1-20. ISBN 978-1-905088-31-7. arch.c.:88081.

[5] STN 73 1402:1988. (1987). Navrhovanie tenkostenných profilov v ocelových konštrukciách. UNM, Praha.

[6] STN EN 1993-1-3:2006 (2006). Design of steel structures - Part 3: Supplementary rules for cold-formed members and sheeting. CEN, Brussels.

[7] STN EN 1993-1-5:2006 (2006). Design of steel structures - Part 5: Plated structural elements. CEN, Brussels.

[8] ANSYS Inc. Release 11.0 Documentation for ANSYS [online]. 2011 <http://www.kxcad.net/>. 